\title{
Account-Making and Confiding as Acts of Meaning in Response to Sexual Assault
}

\author{
Terri L. Orbuch, ${ }^{1}$ John H. Harvey, ${ }^{2}$ Susan H. Davis, ${ }^{1}$ \\ and Nancy J. Merbach ${ }^{3}$
}

\begin{abstract}
A study was conducted to compare the interpretive and coping responses of female and male survivors of incest and female survivors of sexual assault by a nonrelative. Twenty-eight persons responded to a questionnaire that asked them to provide an account of the nature of an assault(s), the role of confidants in helping them cope with the assault, how they coped and tried to understand the assault over time, how they felt the assault affected their close relationships, and how they evaluated their current state of recovery. The results for male and female incest groups were similar in revealing great difficulty in coping and in having adult close relationships. These two groups showed more continuing lack of resolution than did the female nonfamilial survivors. The male group of incest survivors showed the greatest overall difficulty. The findings are discussed in terms of the roles of searching for meaning via account-making and confiding as ways of dealing with long-term, major stressors in people's lives.
\end{abstract}

KEY WORDS: sexual assault; incest; gender; accounts; confiding process.

I suffer from depression constantly, and feel deep inside that I am damaged goods.

(excerpt from 31-year-old male incest survivor in this study)

It hurts like hell . . it's easier to stay sick, stay in denial, commit suicide, stay drunk, or perpetrate the crime onto another victim for relief . .

(excerpt from 36-year-old female incest survivor in this study)

${ }^{1}$ University of Michigan, Ann Arbor, Michigan 48109.

${ }^{2}$ University of lowa, Iowa City, Iowa 52242.

${ }^{3}$ University of Denver, Denver, Colorado 80210.

249 


\section{INTRODUCTION}

Severe incidents of assault such as incest devastate one's sense of control over key aspects of life, make one wary of and even cynical about close relationships, and in general, diminish greatly one's sense of selfesteem and personal identity. The present study was designed to assess the reactions of persons who were willing to provide accounts about incidents of sexual assault, including incest, in their lives. We were concerned principally with their accounts of these events and their subsequent coping, including how the act of confiding about the assault may have related to adjustment.

We approached the topic of coping with sexual assault from a theoretical position that focuses on the social psychology of account-making about severe stress as a facilitator of coping and adjustment (Harvey et al., 1990). We define account-making as people's story-like constructions of events that include explanations, descriptions, predictions about relevant future events, and affective reaction. A major assumption of this theoretical position is that individuals tend to engage in such activity when they are troubled by imposing problems in their lives. Further, they develop subaccounts for particular events that ultimately become woven into larger profiles in the form of a master account of events in their lives. Our work on account-making has examined the role of accounts in various stressful circumstances, including Vietnam combat veterans' reactions to life after the war (Harvey et al., 1989), elderly persons' reactions to the loss of loved ones by death, divorce, and relocation (Weber et al., 1987), and sexual assault survivors' coping with the long-term effect of their trauma (Harvey et al., 1991). Available evidence suggests that well-developed accounts play a salutary role in providing perspective, the will to carry on, hope about the future, and closure regarding such stressors (see reviews by Harvey et al., 1990).

We should note that our work on account-making both overlaps with and runs parallel to a number of lines of theory and research in the social sciences. The concept of accounts was given prominence in the work of Lyman and Scott (1970) in sociology who were amplifying Goffman's earlier influential work on how people present themselves in everyday conduct (e.g., Goffman, 1959). At present, there are active programs of research on how people develop accounts for social predicaments or potentially blameworthy actions (e.g., Cody and McLaughlin, 1994). Our concept of accounts is broader in scope than the concept of accounts emphasized by these scholars in that we are interested in account-making across a variety of situations, including but not restricted to those involving self-esteem protection and enhancement. Also, the accounts concept as we construe it 
overlaps with the idea of narratives and their roles in social behavior (e.g., Gergen \& Gergen, 1988), with conceptions about the value of story-telling as a generally constructive endeavor in life (e.g., Coles, 1989), and to "folk psychology" and people's search for meaning as articulated by Bruner (1990).

In our conception, account-making typically begins in private reflection and may progress quite far before it begins to be reported substantially in confiding activity. Failure to engage in account-making may lead to chronic problems including psychosomatic illness. We view account-making and confiding processes in stress reactions as influenced by a set of general factors that include the gravity and nature of the stressful event, the availability of confidants and their empathic and instrumental capabilities, and the ability and willingness of the individual to engage in account-making and confiding. Although we agree with Coles (1989) that story telling is everyone's universal gift, or bedrock capacity, we also believe that some people are socialized to be more able and willing to engage in account-making and confiding than are others. Expressivity regarding personal issues and trust in others represent two specific manifestations of this ability. Overall, our general thesis is that the reconstructive process occurring after a major trauma will be facilitated greatly by private account-making and confiding in an empathic, helpful other(s). A fuller and recent analysis of the accountmaking and confiding relationship and context is contained in Harvey et al. (1992).

In the present effort, following the research of Harvey et al. (1991), we were interested in respondents' reports of activities related to accountmaking and confiding about the trauma of sexual assault; when the traumatic activities occurred; whether or not the respondents confided in others and, if so, the others' reactions; long-term coping strategies; and perceptions of how the assault affected respondents' close relationships over time. Our ideas about the role of account-making and related confiding in coping with sexual assault are similar to those advanced by Pennebaker $(1985,1989)$ in his influential work showing that victims/survivors of traumatic events often have improved psychological and physical health if they have confided about their trauma. In Pennebaker's research, the focus is on health outcomes associated with confiding behavior, and there is less emphasis on the contents of the confiding act and the social aspects of the interaction with the confidant. The present work involves a somewhat different focus in that we emphasize the contents of the accounts and the social dynamics involved in the confiding experience (e.g., whether or not the confidant is empathic). 
What does the general literature on recovery from sexual abuse tell us about the roles of confiding and/or accounts-type processes in coping? There has been little explicit commentary or research on this process (see Koss, 1990, for a general analysis and review). However, more generally, it is known that women who make sense out of their assault report more success in coping and greater resolution of the experience (Silver et al., 1983). Yet, it is also known that recovery for many persons is a long-term process, and that few victims seek any type of formal help (e.g., counseling) immediately after the assault (Koss, 1985). One may be especially reluctant to seek help when the assault involves incest and the consequence may be shame and feelings of disloyalty toward a member of one's own family.

A number of specific problems have been identified for rape and incest survivors one year or more past the assault, including: fear, mistrust, sexual difficulties, depression, guilt, and marital and relationship problems (Becker et al., 1982; Miller et al., 1982; Quina and Carlson, 1989). As Taylor et al. (1983) suggest, this type of trauma likely challenges a person's belief in personal invulnerability and that the world is meaningful. One of the most common attributional patterns for survivors is the blaming of self, or self-directed negative attribution (Quina \& Carlson, 1989) that may be fed by the reactions of others and the media in analysis of the event. Long-term successful adjustment likely involves the development of an account that provides more in-depth understanding of the event and an interpretation that takes the onus off of self as the responsible agent.

The research by Harvey et al. (1991) reveals the merit of accountmaking and confiding in the coping process of female sexual assault survivors. This past study focused only on women living in Iowa and Western Illinois who had experienced either incest or non-familial sexual assault. Results showed that degree of account-making was positively associated with successful coping and helpful confidant reactions. Also, empathic confidant reactions occurring early after the assault were related to more successful coping than were nonempathic reactions occurring either in the first 12 months after the assault or later. Finally, incest survivors indicated that they had more difficulty in coping than did nonincest survivors. One of the purposes of the present study was to investigate whether the data for women survivors of incest versus non-familial sexual assault would replicate with a population in a different geographical location.

The present study included a sample of male incest survivors, a female group of incest survivors, and a female group of non-familial sexual assault survivors. A major hypothesis of this study was that extent of 
account-making about the traumatic event is positively associated with reported success in coping and negatively related to degree of negative impact on close relationships. A second prediction was that the more empathic the confiding experiences early after the assault, the greater will be the perceived success of coping and positive relating to close others.

Although little work has been done to investigate psychological responses of male survivors of incest, it seems likely that their reaction may reflect even more devastation than female survivors. This possibility is based on the likelihood that incest is a greater stigma in this society for males than it is for females. Males likely have not as yet been as assertive in acknowledging instances of personal assault and in collectively speaking out about the debilitating effects of incest in their lives. Further, in a recent review of research on sexual abuse of boys, Watkins (1992) concluded that available research shows that boys are extremely reluctant to disclose sexual abuse. It is likely, therefore, that male sexual abuse survivors have engaged in less account-making and/or confiding than have female sexual abuse survivors.

Given the foregoing reasoning, we predicted that male incest survivors would exhibit the most severe negative reactions among the three groups in the study. More specifically, we expected that relative to females in either incest or nonfamilial sexual assault groups, male incest survivors would report: (1) the most severe negative reaction to the assault; (2) the least success in coping with the assault; (3) the least extensive account-making activities (e.g., letters, diaries, therapy, private reflection); (4) the least completeness in their account of the assault (i.e., sense of understanding of the assault); (5) the least emotional recovery; (6) the most negative current emotional state regarding the assault; (7) the least success in understanding the assault; and (8) the most negative impact of the assault on their close relationships.

\section{METHOD}

\section{Design and Research Participants}

Twenty-eight men and women responded to advertisements at rape crisis centers in Denver, Colorado, inviting persons to participate in a study of non-consensual sexual activity. Persons interested in participating were asked to contact one of the study's investigators at the university's psychology department to make arrangements to receive and to mail back the study questionnaire. In this contact, confidentiality was 
assured; the investigators emphasized that they did not want to learn the identity of the respondents. There were 12 women in the femaleincest group, seven men in the male-incest group, and nine women in the female-nonfamilial sexual assault group. The respondents ranged in age from 19 to 47 , with a mean age of 34 . There were no significant differences across the groups in age. The average length of time since the assault was 18 years and did not differ across groups. All respondents reported that they had been involved in some type of counseling or support group experience relevant to the assault. All respondents were employed, white, generally middle-class persons living in the Denver Metropolitan Area.

In addition, potential respondents were alerted to the possibility that the act of filling out the questionnaire might be emotionally difficult and that they should consider carefully whether or not they were prepared to answer such questions. Other than the opportunity to contribute to our understanding of the psychological effects of sexual assault, no money or other incentive for participation was offered. Potential respondents also were given the option to receive a reference to counseling services if in their contact they suggested that they really desired formal therapy.

\section{The Questionnaire}

In constructing the questionnaire, we tried to develop items that would permit a test of the theoretical ideas but at the same time allow respondents to freely report on aspects of the assault and subsequent reactions and feelings. Both open-ended and some structured/scaled-response items were included in the questionnaire. This combined approach was designed to enhance the degree of quantitative information obtained beyond the completely open-ended questionnaire technique used by Harvey et al. (1991). We wanted to preserve the flexibility for responding found in the open-ended questions and add, as was feasible, structured items that probed relevant psychological experiences.

The questionnaire included the following principal areas of inquiry in the open-ended format: (1) relationship of the perpetrator to the assault victim; (2) an account of the assault, including information on who perpetrated the assault, where, with what force, and the respondents' thoughts and feelings at the time of the assault; (3) whether or not the respondents had confided in any other person about the assault, and if so, in whom, when, their relationship to the confidant, and the confidant's reactions to the story communicated; (4) their sense of how the 
assault affected them, including how it influenced their close personal relationships; (5) whether or not the respondents blamed some aspect of their behavior for the assault; (6) whether or not they presently felt that they were emotionally recovered from the assault; and (7) an invitation for further comments. Structured or scaled response item questions were included for the following: (1) the reactions of confidants to the respondent's story early after the assault $(0-10$, with higher numbers indicating greater empathy experienced); (2) how much time on average the respondent had spent each month trying to understand the assault $(0-10$, with higher numbers representing more time spent); (3) the overall extent to which they thought the assault had affected negatively their close personal relationships $(0-10$, with higher numbers indicating greater negative impact); (4) the extent to which they felt emotionally recovered from the assault $(0-10$, with higher numbers reflecting greater recovery); and (5) the extent to which they felt successful in achieving an understanding of the assault ( $0-10$, with higher numbers indicating greater success in achieving an understanding).

The initial "full account" commentary and other responses to open-ended questions were coded by two independent raters. Perceived severity of the assault was coded in terms of reported physical and psychological harm caused by the assault. Extent of account-making activity was coded in terms of explicit mention of such activities as journal-keeping, letter-writing, formal therapy centering on the assault, and extensive private reflection pertaining to the assault. Completeness of the account-making was coded in terms of how much understanding of the assault and fulfillment of the process of inquiry the respondent expressed. Empathy of the confidant early after the assault was coded in terms of the extent to which the respondent indicated having engaged in a positive, empathic confiding experience in the first several months after the assault (if no confiding had occurred during the first 2 years after the assault, those respondents' empathy scores were treated differently - see Results). Success in coping was coded in terms of the respondent's indication of how much progress had been made in moving beyond the assault and in dealing with important aspects of life such as work and family. Negative impact on close relationships was coded in terms of explicit mention of how effective the respondent had been in developing and maintaining successful friendships and intimate bondings since the assault. Present negative emotional state was coded in terms of how negative (statements including anger, bitterness, resentment) the respondent felt about the assault at the present time. Across all coding, raters achieved an agreement rate of $87 \%$. 


\section{RESULTS}

First, it should be noted that all 28 respondents provided extensive commentaries on the open-ended and initial account questions. Some respondents even provided additional typed pages of details of the assault and subsequent experiences relevant to the assault. A few, however, provided incomplete answers on structured items. Similarly, a few commented that the structured items did not permit them to present a full measure of their experience. The question of format of questions employed in the questionnaire and their apparent differential sensitivity to respondents' experience will be examined in the discussion section.

For both male and female incest groups, the father was the dominant category for the perpetrator of the sexual assault. Three of these females and four of these males reported multiple perpetrators. A dating partner or an acquaintance was the dominant reported perpetrator for the female nonfamilial group. Two of these females reported multiple perpetrators.

All 28 respondents indicated that they had at least tried to confide in someone within two years after the assault. Confidants were close friends, parents and relatives, therapists, and therapy groups. Across conditions, no systematic difference in type of confidant was observed. The type of response by confidant varied from shock, embarrassment, denial, and indifference to empathy and support. Examples of respondents' statements about their confiding experiences included: (from a 37-year-old woman assaulted by her father) "Everyone I mentioned it to has been at a loss for words for what to say ... .I usually receive denial or blank expressions and avoidance;" (from a 26-year-old woman assaulted by her brother) "The people that I have discussed this rape with have been close and good friends, my lover, and my parents. All of them were very supportive and have tried hard to help me work through my guilt;" (from a 40-year-old man who was assaulted by his father as a child) "My mom really did not know what to say (and she also has emotionally incested me) and says she didn't know it happened. My sister said she believed me, but passed it off by saying that it probably happens in many families..."

\section{Correlational Evidence}

Table I presents correlations for the variables for which at least some significant evidence emerged. The variables listed in this Table are: (1) perceived severity of assault; (2) extent of account-making relevant 


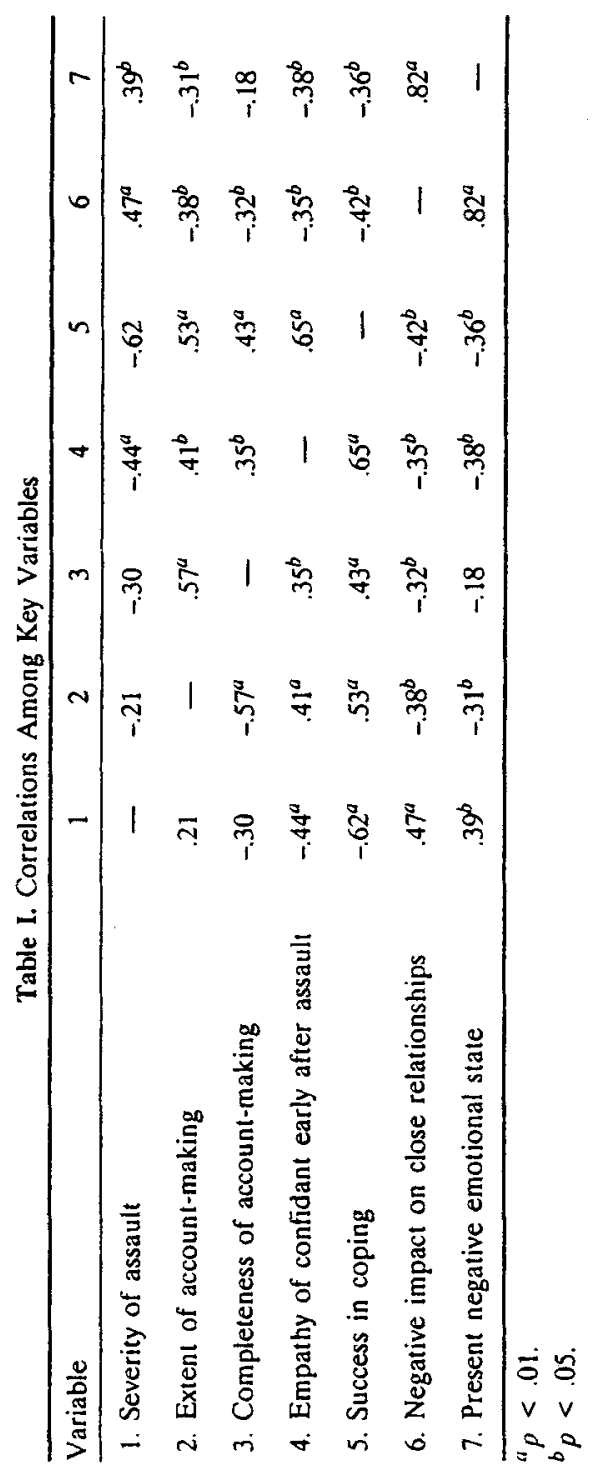


to assault; (3) completeness of account-making in terms of understanding of the assault; (4) empathy of the confidant early after the assault; (5) success in coping with the assault; (6) degree of negative impact of the assault on the respondent's close relationships; and (7) present negative affect associated with assault. Unexpectedly, the only structured question that yielded any modest correlational evidence was rated empathy of confidant early after the assault. This variable showed a pattern of evidence that mirrored that of coded empathy of confidant (the variable listed in Table I). All of the variables listed in Table I were developed via coding open-ended responses.

As can be seen from Table I, several of the significant correlations are consistent with the hypotheses of this study. These include: Perceived severity of assault was negatively related to success in coping and positively related to degree of negative impact on close relationships. Extent of account-making and completeness of account-making were positively related to success in coping and negatively related to degree of negative impact on close relationships. Empathy of confidant early after the assault was positively related to extent of account-making, completeness of accountmaking, and success in coping, and was negatively related to degree of negative impact on close relationships and to present negative emotional state associated with the assault. Overall, the highest correlation in Table I (.82) is between degree of negative impact on close relationships and present negative state associated with the assault. This strong relationship may suggest how important later positive close relationships are to persons experiencing sexual assault and how difficult it is for them to have such relationships.

\section{Comparisons Among Groups}

It was predicted that the male group would differ from the two female groups on a number of dimensions, reflecting males' greater difficulty in dealing with sexual assault. In general, the data support this overall hypothesis.

The group comparison predictions were tested by one-way ANOVA's and, when significant main effects emerged, $t$-tests were conducted to further differentiate groups. Significant main effects were found for the following variables: (1) severity of the assault $[F(2,25)=7.3, p<.01]$; (2) extent of account-making $[F(2,25)=4.3, p<.05]$; (3) completeness of account-making $[F(2,25)=4.1, p<.05] ;(4)$ success in coping $[F(2,25)=4.6, p<.05] ;(5)$ blame of self $[F(2,25)=9.5, p<.001]$; and (6) rated success in understanding the assault $[F(2,25)=6.9, p<.01]$. It is instructive to note that the main 
Table II. Means of Measures Differing Significantly for Three Groups of Respondents ${ }^{a}$

\begin{tabular}{lccc}
\hline Measures & Male-Incest & Female-Incest & $\begin{array}{c}\text { Female- } \\
\text { Nonfamilial }\end{array}$ \\
\hline Severity of assault & $9.64^{a}$ & $8.29^{b}$ & $6.11^{c}$ \\
Extent of account-making & $2.31^{a}$ & $4.75^{b}$ & $4.49^{b}$ \\
Completeness of account-making & $5.64^{a}$ & $6.63^{b}$ & $8.39^{c}$ \\
Success in coping & $1.57^{a}$ & $3.38^{b}$ & $5.28^{c}$ \\
Blame self & $2.71^{a}$ & $7.25^{b}$ & $3.67^{a}$ \\
Rated success in understanding assault & $3.29^{a}$ & $7.13^{b}$ & $7.00^{b}$ \\
\hline
\end{tabular}

${ }^{a}$ Different subscripts indicate that means are significantly different by individual comparison at $p<$ at least .05 .

effects for degree of negative impact on close relationships and empathy of the confidant early after the assault approached significance $(p<.07$ and $p<.06$, respectively). Means for the variables producing significant main effects are reported in Table II.

Individual comparisons among means for the significant main effects revealed the following patterns (all by two-tailed, t-tests): (1) severity of assault - male-incest group greater severity than female-incest group $(p<.01)$ and greater than female-nonfamilial group $(p<.01)$; also, female- incest greater severity than female-nonfamilial $(p<.05)$; (2) extent of account-making - male-incest group less account-making than female-incest group $(p<.05)$; and less than female-nonfamilial group $(p<.05)$; the latter two groups did not differ significantly; (3) completeness of account-making - female-nonfamilial group greater completeness than male-incest group $(p<.01)$ and greater than female-incest group $(p<$ .05 ); also, the female-incest group showed greater completeness than did the male-incest group $(p<.05)$; (4) success in coping - female-nonfamilial group greater success than male-incest group $(p<.05)$; also, the femaleincest group showed greater success than did the male-incest group $(p<$ $.05)$; (5) blame of self - female-incest group greater self blame than maleincest group $(p<.01)$ and greater than female-nonfamilial group $(p<$ .001 ); also, the male-incest group and the female-nonfamilial group did not differ; (6) rated success in understanding the assault - male-incest group less rated success than female-incest $(p<.001)$ and less than female-nonfamilial group $(p<.01)$; the latter two groups did not differ significantly. Finally, for the $(p<.06)$ main effect for empathy of the confidant early after the assault, a one-tailed $t$-test showed that the female-nonfamilial group reported greater empathy than did the male-incest group $(p<.05)$ and the female-incest group $(p<.05)$. 


\section{Descriptive Evidence: \\ Excerpts from Respondents' Open-Ended Answers}

Despite the reported quantitative differences between groups reported in the previous sections, the degree of psychological devastation was great in all three groups. The following excerpts are presented as illustrations of the nature of the severity of the respondents' reports. They provide greater insight into the experience of some of the respondents.

First, two male incest survivors report on the long term impact that sexual assault has on their lives. A 47-year-old male provided the following comments regarding the severity of his experience of being assaulted between the ages of 3 and 12 by his father, cousin, and men who worked at his family's home: "It has affected every portion of my external and internal life for the last 44 years. Close relationships? I don't have any, and never have had ... And I've been married for 25 years now! But it is not a close, personal or intimate relationship. If anything, it is abusive to me. I don't trust anyone ..."

A 31-year-old male who was assaulted for four years between the ages of 3 and 7 by his father and family friend provided this remark about the consequences of the assault: "I suffer from depression constantly, and feel deep inside that I am damaged goods."

Turning to comments made by female-incest respondents, we find reports that are similar to those of the male-incest respondents in terms of horror experienced and degree of psychological devastation. A 37-year-old woman who was assaulted both by her father and mother from early in her life to age 17 reports these repercussions: "Any experience of getting close to someone is accompanied by feelings of fear, inadequacy, distrust, lack of boundaries. Even relatively simple interactions can trigger these feelings ..."

Finally, females abused by nonrelatives also depicted experiences of terror, as revealed in the following remarks by a 41-year-old woman raped by an acquaintance: "I went into a deep depression and disassociated. It was as if I was watching myself go through the motions of living but wondering all the time how I was functioning. I've been unable to hide how I feel. The pain has been awful."

\section{DISCUSSION}

In this study, we were interested in the roles of account-making and confiding as part of the coping response to sexual assault. We were particularly interested in male survivors' responses as compared to female 
survivors' responses. The results afforded considerable support to the hypotheses of the study. As predicted, extent of account-making was positively associated with success in coping and negatively associated with degree of negative impact on close relationships. The same set of associations occurred for completeness of account-making, success in coping, and degree of negative impact on close relationships. These results suggest the value of account-making activity in expressing emotions about the assault; cognitively clarifying aspects of the assault; resolving some of the resultant anger, fear, and paralysis of action; and actually moving on with one's life constructively.

Also as predicted, it was found that the more empathic the confiding early after the assault, the greater the successful coping and the less the negative impact of the assault on close relationships. Empathy also was positively associated with extent and completeness of account-making. From our perspective, empathic confiding and relatively complete accountmaking are essential for healing to occur. Further, confiding and account-making complement and reinforce one another.

The general finding in this study regarding the value of confiding about sexual assault that is met with a helpful reaction by others is consistent with evidence reported by Andrews and Brown (1988) who conducted research with a sample of women who had suffered spousal abuse in England. In their study, women who were abused by their husbands and who then experienced nonoptimal confiding encounters with others (e.g., rejection or obvious attempts to avoid discussion of the issue) showed various negative reactions such as characterological self-blame (i.e., blame of one's own personality or other personal qualities) (Janoff-Bulman, 1979).

Probably the most important objective of this work was to compare males' and females' responses to questions about their experience of sexual assault. At present, too little research has been conducted on gender differences in this area. Our predictions were that over several dimensions, males would report greater distress than would females. The data provide a moderate degree of support for these predictions. They also reveal that the female-incest group reported more negative reactions overall than did the female-nonfamilial sexual assault group. Of the three groups sampled, male-incest survivors showed significant differences reflecting less recovery from the assault for the variables of severity, extent and completeness of account-making, success in coping, and success in understanding the assault. Female-incest survivors tended to fall somewhat in the middle between male-ircest and female-nonfamilial survivors. Female-incest survivors, however, did show more difficulty in recovery across the variables of severity, completeness, success in coping, and blame of self than did the 
female-nonfamilial survivors. For the blame of self variable, female-incest survivors exhibited the most difficulty across the three groups. This latter finding may be understood in terms of the greater burden the American culture traditionally has placed on women relative to men for taking either explicit or implicit actions leading to sexual transgressions. Such a burden may be especially felt by female incest survivors.

The format of questions used in this study yielded decidedly disparate patterns of data. The open-ended questions were much more sensitive to respondents' experiences than were the structured-questions. Reasons for this difference in sensitivity may be found in the nature of the questionnaire as well as the task of telling others about probably the most distressing and intimate details of one's life. As a few suggested, the structured items may not have done justice to such a full and detailed presentation. These respondent comments coincide with a similar form of evidence deriving from Harvey et al. (1991) that sexual assault survivors willing to devote considerable time to giving answers about their experience appreciated an open-ended format for most questions. Based on our program of research, we believe that a strong merit of open-ended measures (coupled, as is possible, with more structured measures) is that the scholar and clinician can gain a much clearer appreciation of the depth of impact for and continued suffering of survivors than is possible with only structured measures.

A final area of evidence deserving commentary is that, on practically all measures, incest survivors exhibited more difficulty in recovery than did nonfamilial survivors. These results may be related to evidence reported by Roth and Lebowitz (1988) in a study of psychological effects of sexual trauma. Their work emphasized a case-history approach for a small sample of individuals who were seeking treatment. Themes such as rage, helplessness, fear, self-blame, isolation, and alienation were common in the reports by Roth and Lebowitz's sample. As suggested by the excerpts from the accounts reported by participants in our study, such themes also were observed, and especially so in the reports of the incest group.

This reasoning brings us to the final topic of the limitations of this study. First, the sample was quite small and limited to the Western United States. We believe that other investigators may encounter considerable difficulty in securing male participants and will need to go to great lengths to enlist a sample of male sexual assault survivors. We now have engaged three years of diligent work with community agencies in various parts of the country attempting to secure a sizeable group of male sexual assault survivors for our research. At present, we still have secured only a modest number of male respondents across different investigations. 
We also have only a modicum of evidence about the role of factors such as social attitudes and beliefs, religious up-bringing, substance abuse, or the objective nature of the social support network that may have affected the survivors' responses. Nonetheless, the sample provided considerable variation along the dimension of perceived severity of assault and rated impact of assault in the respondents' lives.

A major limitation of the study is the self-selected nature of the sample. Participants in this study may differ in a number of ways from people who decided not to participate. They may want to "tell their message" more strongly and be closer to resolution as compared to persons who elected not to participate. They may be (or have been) more involved in therapy and related account-making and confiding than are/were those who elected not to participate. They may even be better off psychologically than are persons who elected not to participate.

We also do not provide good cause-effect evidence about the roles of account-making and confiding in the coping process. Our evidence mainly is correlational and open to a variety of third-variable issues such as the possibility that certain personality factors account for health quite apart from the activities of account-making and confiding. Another intriguing question is, for those individuals who cope better, does private intensive account-making occur before public, productive confiding, or does such confiding lead to more intense account-making? Our study cannot establish a causal direction for these central processes. In future studies, we hope to collect more in-depth longitudinal data from a larger sample of female and male survivors to alleviate many of these limitations.

In conclusion, this work suggests that people's accounts of pain and anguish and their telling of aspects of such accounts to empathic confidants may represent invaluable acts of meaning [to paraphrase Bruner's (1990) thesis] in the recovery process of survivors of trauma. Such acts may be essential to the will to recover and to other behavioral steps toward recovery. Whatever our role is vis a vis the survivor of sexual assault, we believe that we have an obligation to appreciate and respect the suffering that others have experienced and that accounts similar to the ones reported in this work have great potential to help all of us connect better with a world of suffering that always is right at our doorstep.

\section{REFERENCES}

Andrews, B., and Brown, G. (1988). Social support, onset of depression and personality: An exploratory analysis. Social Psychiatry Psychiatric Epidemiol, 23: 99-108.

Becker, J. V., Skinner, L. J., Abel, G. G., and Treacy, E. C. (1982). Incidence and types of sexual dysfunctions in rape and incest victims. $J$. Sex Marit. Ther., $1: 65-74$. 
Bruner, J. (1990). Acts of Meaning. Cambridge: Harvard University Press.

Cody, M., and McLaughlin, M. (1994). In H. Giles, and P. Robinson (eds.), Interpersonal accounting. The Handbook of Language and Social Psychology, Wiley, London.

Coles, R. (1989). The Call of Stories, Houghton Mifflin, Boston.

Gergen, K., and Gergen, M. (1988). Narrative and the self as relationship. In L. Berkowitz (ed.), Advances in experimental social psychology, Academic Press, Orlando, pp. 17-56.

Goffman, E. (1959). The Presentation of Self in Everyday Life, Doubleday-Anchor Books, Garden City, NY.

Harvey, J., Agostinelli, G., and Weber, A. (1989). Account-making and formation of expectations about close relationships. Rev. Personal. Social Psychol. 10: 39-62.

Harvey, J., Orbuch, T., Chwalisz, K., and Garwood, G. (1991). Coping with sexual assault: The roles of account-making and confiding. J. Traum. Stress, 4: 515-531.

Harvey, J., Orbuch, T., and Weber, A. (1990). A social psychological model of account-making in response to severe stress. J. Lang. Social Psychol. 9: 191-207.

Harvey, J., Orbuch, T., Weber, A., Merbach, N., and Alt, R. (1992). House of pain and hope: Accounts of loss. Death Studies 16: 1-26.

Harvey, J., Weber, A., and Orbuch, T. (1990). Interpersonal Accounts: A Social Psychological Perspective, basil Blackwell, Oxford.

Harvey, J., Wells, G., and Alvarez, M. (1978). Attribution in the context of conflict and separation in close relationships. In Harvey, J., Ickes, W., and R. Kidd (eds.), New Directions in Attribution Research, Earlbaum, Hillsdale, NJ, pp. 235-259.

Horowitz, M. (1986). Stress Response Syndromes (second edition), Jason Aronson, Northvale, NJ.

Janoff-Bulman, R. (1979). Characterological versus behavioral self-blame: Inquiries into depression and rape. J. Personal. Social Psychol. 37: 1798-1809.

Koss, M. (1983). The hidden rape victim: Personality, attitudinal, and situational characteristics. Psychol. Wom. Quanterly, 12: 1-24.

Koss, M. (1985). Violence against women. Am. Psychologist, 45: 374-380.

Lyman, S., and Scott, M. (1970). A Sociology of the Absurd, Appleton-Century-Crofts, New York.

Miller, W. R., Williams, A. M., and Berstein, M. H. (1982). The effects of rape on marital and sexual adjustment. Am. J. Fam. Ther. 10: 51-58.

Pennebaker, J. (1989). Confession, inhibition, and disease. In L. Berkowitz (ed.), Advances in Experimental Social Psychology, Academic Press, Orlando, pp. 211-244.

Pennebaker, J. (1985). Traumatic experienced and psychosomatic disease: Exploring the roles of behavioral inhibition, obsession, and confiding. Canad. Psychol. 26: 82-95.

Quinca, K., and Carlson, N. L. (1989). Rape, Incest, and Sexual Harassment: A Guide for Helping Survivors, Praeger, New York.

Roth, S., and Lebowitz, L. (1988). The experience of sexual trauma. J. Traum. Stress, 1: 79-107.

Silver, R., Booth, C., and Stones, M. (1983). Searching for meaning in misfortune: Making sense of incest. J. Social Issues 39: 81-102.

Taylor, S., Wood, J. V., and Lichtman, R. R. (1983). It could be worse: Selective evaluation as a response to victimization. J. Social Issues, 39: 19-40.

Watkins, B. (1992). The sexual abuse of male children and adolescents: A review of current research. J. Child Psychol. Psychiatry 33: 197-248.

Weber, A., Harvey, J., and Stanley, M. (1987). The nature and motivation of accounts for failed relationships. In R. Burnett, P. McGhee, and D. C. Clark (eds.), Accounting for Relationships, Methuen, London, pp. 114-133.

Weiss, R. (1975). Marital Separation, Basic Books, New York. 